\title{
HISTOLOGY AND ULTRASTRUCTURE OF THE ADRENAL GLAND OF THE GREATER CANE RATS (THRYONOMIS SWINDERIANUS, TEMMINCK 1827)
}

\author{
CASMIR ONWUASO IGBOKWE \\ Department of Veterinary Anatomy, Faculty of Veterinary Medicine, University of Nigeria, Nsukka, \\ Nigeria. Email:casmir.igbokwe@unn.edu.ng.
}

\begin{abstract}
The adrenal glands of domesticated greater cane rats (Thryonomys swinderianus), were studied using histological and ultrastructural techniques. A total of seven (7) adult male greater cane rats, aged from 10-14 months, with an average weight of $1.89 \mathrm{~kg}$ (range: $1.6-2.2 \mathrm{~kg}$ ) were used in this study. The results showed variations in the thickness of the zones of the cortex and medulla. Histological detail did not differ significantly from that of other rodents. Ultrastructural features showed typical adrenal gland zonation with capsule, cortical cells and medulla. In the cortex copious lipid droplets and myelin bodies were present. The cortical cells of the zona fasciculata contained concentric whorls of rough endoplasmic reticulum that enclosed2-3 mitochondria. Adrenaline storing (A) and noradrenaline-storing (NA) chromaffin cells along with few vesicular ganglion cells were identified in the medulla. The functional significance of the present observation is discussed.
\end{abstract}

Keywords: adrenal gland, cane rats, histology, ultrastructure

\section{INTRODUCTION}

The adrenal gland is known to be essential foraturation of some fetal organ-systems such as liver, mammalian life as it produces a number of importahtng, thyroid gland and gastrointestinal tract (Liggins, hormones including cortisol, adrenaline, androgens aril976). In some species such as goat, sheep and rabbit, aldosterone (Mitani, 2014). Mineralcorticoids producedrtisol from the adrenal cortex of the fetal adrenal in the zona glomerulosa contribute to homeostasis gfands regulate the timing of parturition (Mesiano and electrolytes and the volume of circulating fluid mainjaffe, 1997).

through the stimulation of resorption of water, sodium

and potassium ion excretion. The glucocorticoidts is well known that there are species and sex synthesized in the zona fasciculata regulate thaffferences in the structure of adrenal gland and metabolism of carbohydrates, proteins and lipidisnction, particularly in the distribution and (Jelinek and Konecny, 2011). Adrenaline aredncentration of steroidogenic enzymes of the adrenal noradrenaline (catecholamines) produced in thertex (Ishimura and Fujita, 1997). Studies on the adrenal medulla have profound effect on the blocstructure and functional morphology of the adrenal haemodynamics by vasoconstriction, vasodilation argland in several mammals exist (Idelman, 1970; by direct effect on cardiac activity (Hullinger antussdorfer, 1980; Nussdorfer, 1986; Kobayashi and Andrisani, 2006).Androgens secreted in the zoreaupland, 1993; Crivellato et al.,2008). However, little reticularis and in the inner layer of the zona fasciculataformation is available on the structure of the adrenal are transformed to active forms of testosterone argland in the greater cane rat. This study focused on oestrogen in target organs (Jelinek and Konecnlyistological and ultrastructural features of the adrenal 2011). The importance of adrenal gland is also shougland in adult cane rats in order to contribute to the during prenatal development as the steroid hormonesngoing attempts to understand its biology and produced by the fetal adrenal cortex helps in tramestication.

Submitted $7^{\text {th }}$ June 2016, revised on $7^{\text {th }}$ September 2016. Published online $12^{\text {th }}$ January 2017 . To cite: Igbokwe CO. Histology and Ultrastructure of the Adrenal Gland of the greater cane rats . Anatomy Journal of Africa. 2017. Vol 6 (1): $873-883$.

867 


\section{MATERIALS AND METHODS}

Animals: A total of seven (7) adult male greater cane rats, aged from 10-14 months, with an average weight of $1.89 \mathrm{~kg}$ (range: 1.6 $-2.2 \mathrm{~kg}$ ) were used in this study. They were purchased in March (dry season) 2014 from a breeding farm (David Mark Farms, Oturkpo, Benue State, Nigeria). Animals were maintained on elephant grass (Pennisetum purpureum) and feed supplement, and water was given ad libitum for seven days before they were sacrificed. The live weight of each animal was determined after sedating with Thiopental sodium $(20 \mathrm{mg} / \mathrm{kg}$, Rotexmedica, Trittau, Germany) and subsequently euthanized with lethal dose of same drug. After death, the adrenal glands were dissected by ventral abdominal incision to expose the caudal pole of the kidneys on the lumbar region. The left and right adrenal glands were removed, the surrounding fat tissue trimmed-out and weighed.

Microscopy: For light microscopy, the adrenal glands were fixed in $10 \%$ neutral buffered formalin. They were processed routinely, blocked in paraffin and cut in $6 \mu \mathrm{m}$ sections. The cut sections were stained routinely with haematoxylin and eosin ( $\mathrm{H} \& \mathrm{E})$ for general detail, and observations photographed. For histometry, an ocular micrometer gauge calibrated with a stage micrometer was used to obtain values of histological parameters of the gland such as thickness of the capsule, zona glomerulosa, zona fasciculata and medulla from selected sections under a light microscope with $\times 10$ objective lens.

For electron microscopic study, adrenal glands were diced into $2 \mathrm{~mm}^{3}$ cubes and immersionfixed for a minimum of 24 hours in $2.5 \%$ glutaraldehyde in Millonig's phosphate buffer (pH 7.4 and 0.12M). Samples were washed in Millonig's phosphate buffer and post-fixed in similarly buffered $1 \%$ osmium tetraoxide for 1 to 2 hours. They were dehydrated through a graded series of ethanol, infiltrated with propylene oxide, embedded in Epon epoxy resin and cured overnight at $60^{\circ} \mathrm{C}$. Semi-thin sections $(0.5-1 \mu \mathrm{m})$ were cut and stained with toluidine blue and examined by light microscopy for identification of suitable areas for thin sectioning. Suitable areas of interest were identified and ultra-thin sections (60$80 \mathrm{~nm}$ ) were cut and contrasted with uranyl acetate and lead citrate. Sections were viewed with a Philips CM10 Transmission electron microscope (Eindhoven, The Netherlands) operated at $80 \mathrm{kV}$ and images captured with a iTEM MegaView $®$ (Olympus Soft Imaging Solutions, Munster, Germany) digital camera. The author wish to state that all procedures involving animals were carried out according to the guidelines for experimentation and protection of animal welfare in the University of Nigeria Nsukka, Enugu State, Nigeria as provided by Research Ethics Committee (2005).

\section{Light Microscopic features}

The right and left adrenal glands measured $45.2 \pm 0.8 \mathrm{mg}$ in mean weight.

Histological overview of the adrenal gland showed a thin outer capsule that covered typical discernable zones of the gland comprising, zona glomerulosa, a wider zona fasciculata and a much thinner zona reticularis that merged with outer region of the medulla, followed by inner region of the medulla (Fig.1). The capsule consisted of connective tissue fibers with some spindle-shaped

\section{RESULTS}

fibroblasts and smooth muscle fibres. It measured approximately $25.7 \pm 4.4 \mu \mathrm{m}$ in thickness (range, 21.7-31.2 $\mu \mathrm{m}$ ). The zona glomerulosa consisted of cells in 2-3 clusters (Fig.2). These cells were round with dark spherical nuclei and eosinophilic cytoplasm. Somevacuoleswere evident in the cytoplasm of some of the cells. It measured $64.5 \pm$ $9.7 \mu \mathrm{m}$ in thickness (range, 53.5-80.5 $\mu \mathrm{m}$ ). The zona fasciculata was the widest cortical zone and measured $720.6 \pm 18.6 \mu \mathrm{m}$ (range, $686.4-736.8 \mu \mathrm{m}$ ). It consisted of polyhedral or cuboidal cells arranged in irregular cords of one-cell thickness (Fig.3). The cytoplasm was 
eosinophilic with highly vacuolated 'foamy' appearance due to the presence of small and large oval lipid droplets. The lipid droplets were more in number in the part towards the zona reticularis. The nucleus was darkly stained with clumps of chromatin material. The cords of cells were separated by intervening fine strands of connective tissue and copious vascular sinuses. The zona reticularis was not easily distinguished from the fasciculata, It measured $106.3 \pm 14.5 \mu \mathrm{m}$ (range: 96.2-116.6 $\mu \mathrm{m}$ ) in thickness. The cells were in anastomosing cords projecting in different directions (Fig.4). They varied in size and shape. The cords of cells were separated by extensive vascular sinuses which merged with the outer medullary zone. Lipid droplets were less frequently encountered in this zone.
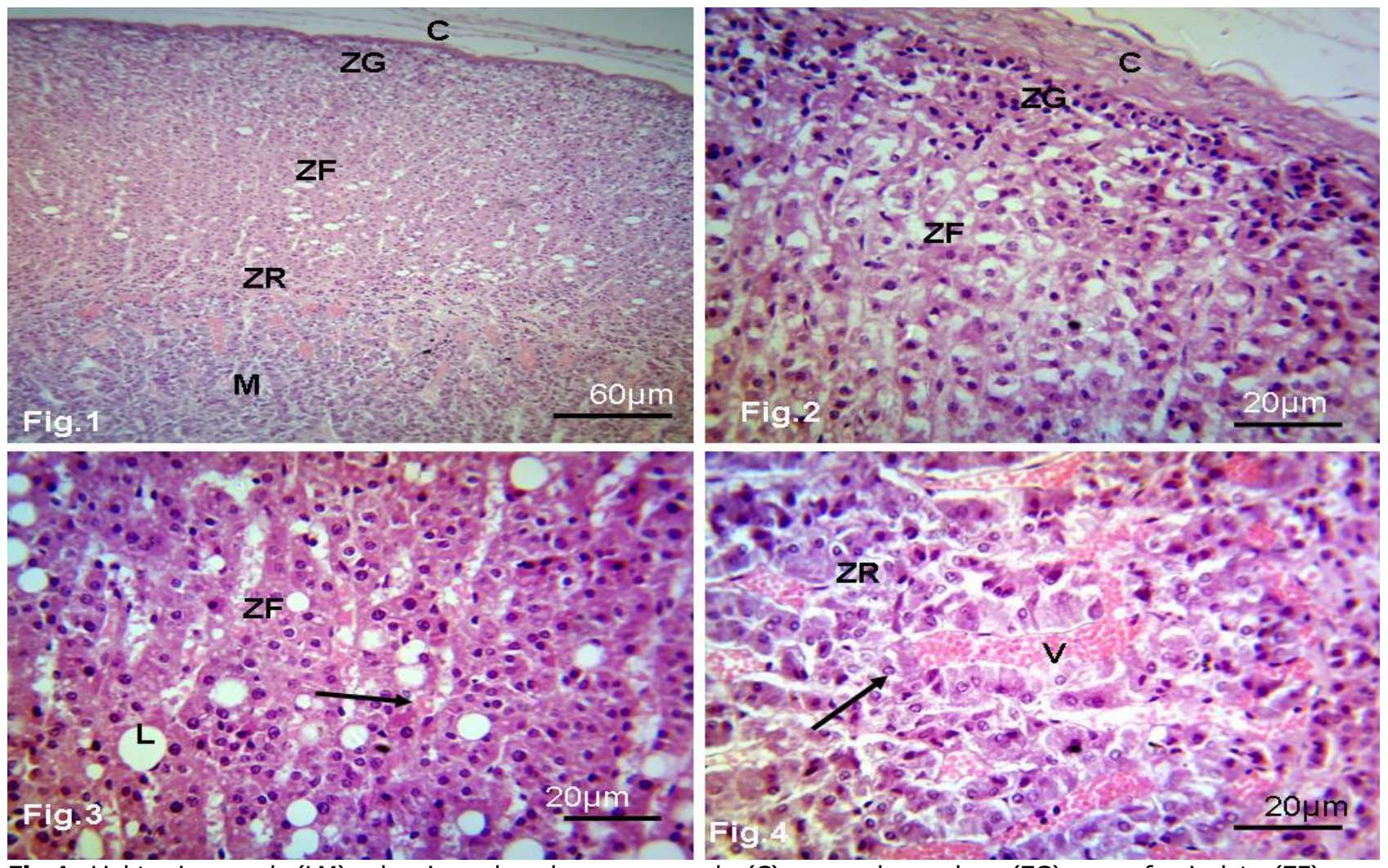

Fig.1: Light micrograph (LM) showing adrenal zones, capsule (C), zona glomerulosa (ZG), zona fasciculata (ZF), zona reticularis (ZR) and medulla (M). Fig.2: Higher magnification of adrenal cortex. capsule with collagenous tissue (C), glomerulosa with clusters of cells (ZG) and fasciculate (ZF). Fig.3: LM of adrenal gland showing arrangement of cells (ZF) with copious lipid droplets (L) of varying size. . Fig.4: LM of Adrenal gland showing high vascularisation (V) of zona reticularis (ZR) with anastomosing cell cords (arrow). H \& E.

The medulla measured $636 \pm 11.5 \mu \mathrm{m}$ (range; 625.1-957.3 $\mu \mathrm{m}$ ). The parenchyma consisted of polyhedral chromaffin cells with large elliptical nucleus and they were in cords or clusters, forming a compact network and with occasional ganglion cells (Fig.5). The cytoplasm contained granules. The groups of cells were surrounded from outside by a basement membrane and sinusoids passed through these clusters. At the outer zone of the medulla close to the cortico-medullary border, extensive vascular sinuses were present. The cytoplasm of the cells was basophilic and granular with vacuolation in some of the cells. Some brown pigments in these cells appeared to be lipofuscin pigments (Fig.6).The ganglion cells were polygonal in shape with prominent nuclei and separated by sinusoids. The supportive framework of the medulla consisted of loose connective tissue and the numerous large venous sinuses. 

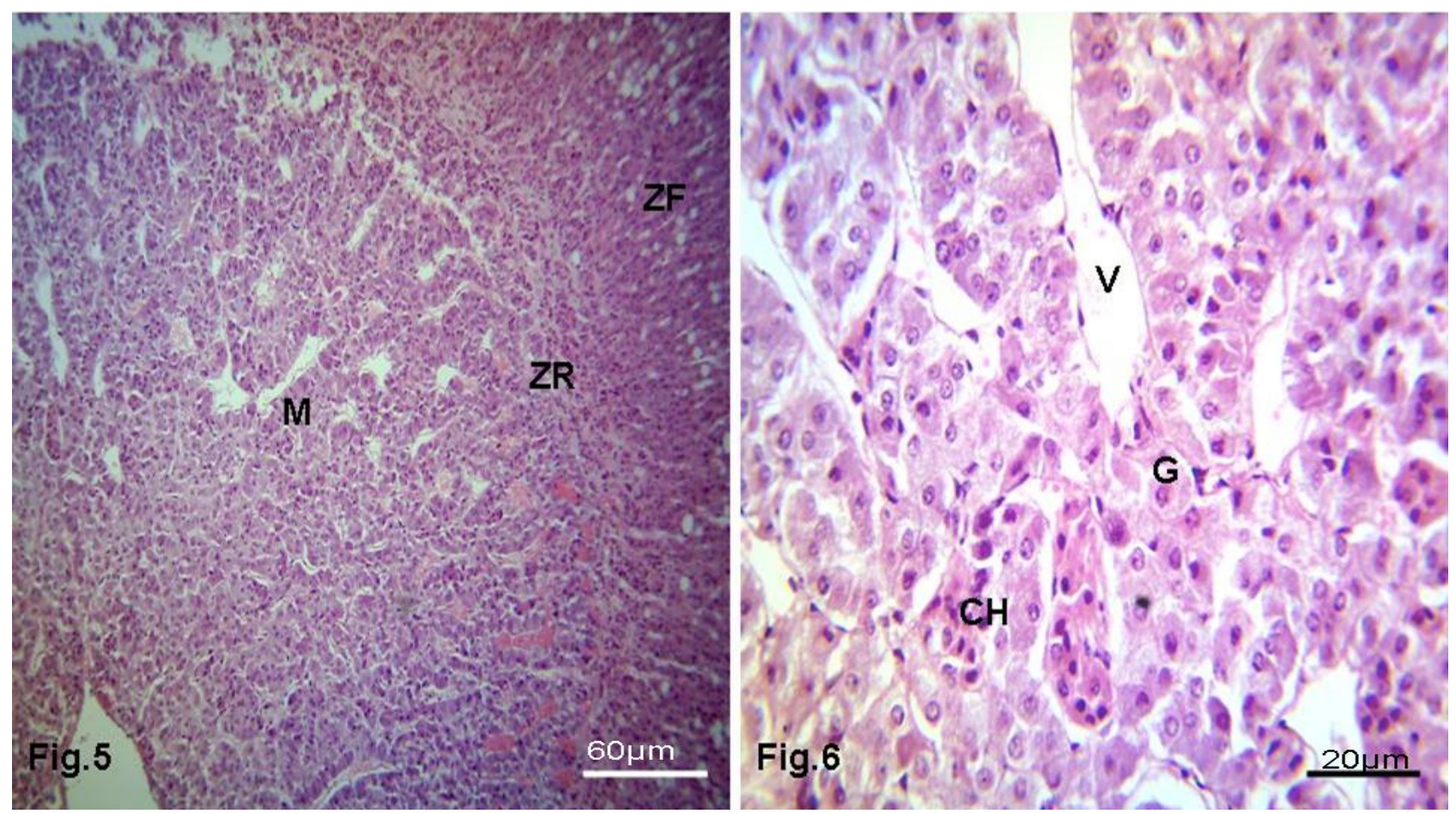

Fig.5: LM of adrenal gland medulla showing an indistinct demarcation from zona reticularis (ZR) and zona fasciculata (ZF). Fig 6: LM of adrenal medulla copious vascular sinuses $(\mathrm{V})$, chromaffin cell clumps $(\mathrm{CH})$ and ganglion cells (G). H \& E.

\section{Ultrastructural features}

The capsule consisted of 5-7 layers of elongated connective tissue fibroblasts embedded inside a collagenous framework. Short connective trabeculae from the capsule penetrated into the cortex (Fig.7). These cells with long cytoplasmic processes were recognized as fibroblasts. Some unmyelinated nerve fibres were apparent in the capsule. The nuclei of the capsular cells were elongated and varied in shape with nuclear indentations. The nuclei were surrounded by scant cytoplasm that contained few mitochondria, Golgi complex amongst other intracellular organelles. Red blood cells were present in the extracellular space. Collagen fibrils were well developed and distributed throughout the gland. Capillaries were occasionally observed (Fig.8).The zona glomerulosa (ZG) consisted of loops of 2-3 groups of cortical cells located just beneath the capsular connective tissue layer (Fig.9). Each group of cortical cells in the ZG was surrounded by a basement membrane and thin connective tissue sheath that contained capillaries. Each cell is bounded by its plasma membrane and separated from other cells by a small pericellular space. The nuclei were oval and smaller than that of the following cortical cells of zona fasculata (ZF). The nuclei were euchromatic (Fig.10). The cytoplasm contained abundant mitochondria, mainly oval in shape with few elongated profiles. The crista were tubular, vesicular and tubulovesicular in some sections. Golgi apparatus was prominent. Lipid droplets were scant compared to the ZF. Smooth endoplasmic reticulum was well developed and rough endoplasmic reticulum were scanty. 

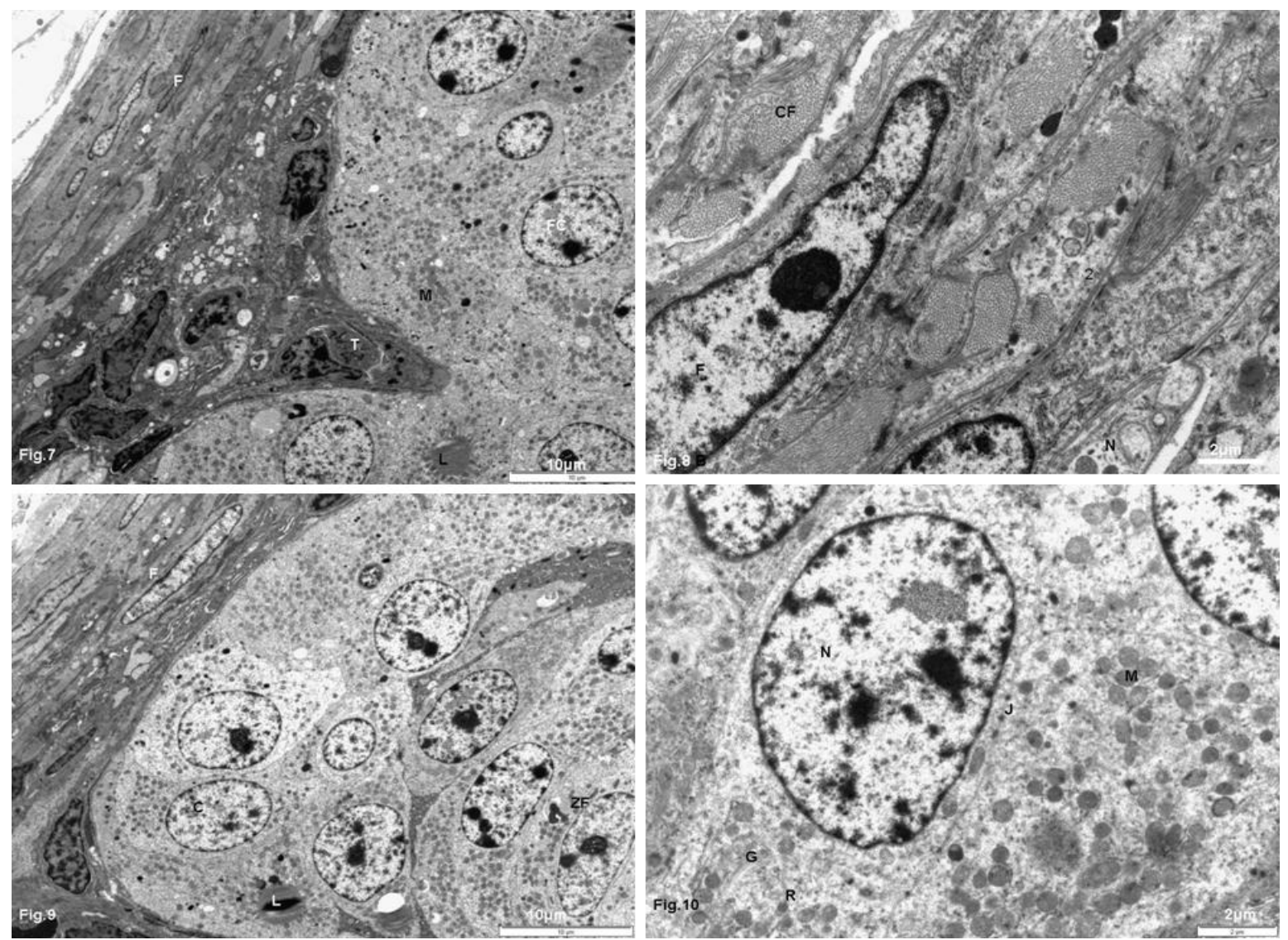

Fig.7: Electron micrograph (EM) of capsule of adrenal gland showing fibroblasts $(F)$, trabeculae with connective tissue cells $(T)$, cortical cells of zona glomerulosa with profiles of mitochondria (M). Fig.8: EM of capsule showing cellular and connective tissue components, collagen fibrils (CF), fibroblast (F), nervous elements (N), basement membrane (B).. Fig.9:EM of zona glomerulosa (ZG) and fasciculata showing clusters of cortical cells, cortical cells of ZG (C), lipid droplets (L), cells of fasciculata (ZF) and fibroblast (F). Fig.10: EM of cortical cell of ZG showing cell nucleus (N), oval mitochondria (M) and well defined intercellular junction (J) and Golgi complex (G). Free ribosomes (R) are scattered in the cytoplasm.

In the zona fasciculata, the cells at low view were arranged in relatively long fascicles. Lipid droplets

were most frequently encountered in the cytoplasm of the cells of the ZF than other zones (Fig.11). Specifically, the cells of the inner portion of this zone showed cells with considerable number of intracellular lipid droplets than the outer portion. In some sections, lipid droplets were frequently surrounded by elongated mitochondria or groups of it and very close to vascular spaces (Fig.12). Numerous mitochondria which possessed a tubular or tubulo-vesicular internal structure (cristae) were apparent. In the outer portion, smooth endoplasmic reticulum (SER) was highly abundant in the cells and largely in tubular form. The SER was closely apposed to the mitochondria and lipid droplets. Free ribosomes were scattered in the cytoplasm. In addition few dense lysosome-like bodies with heterogeneous internal materials were frequently seen. The Golgi apparatus was typical. A microvillous projection of the cortical cells in the ZF was apparent. In the inner portion of the ZF lipid droplets were more frequently encountered in the cells than in the outer portion. In entire $\mathrm{ZF}$, intercellular junctions were well developed; particularly desmosomes were frequently seen throughout the cortex. In sections of the ZF, several projections of whorled membranes into the lipid droplets of the cortical cell were observed and represented myelin figures (Fig.13). A prominent feature of the cortical cells of the $\mathrm{ZF}$, observed close to the zona reticularis (ZF$\mathrm{ZR}$ border) was the presence of concentric 
Anatomy Journal of Africa. 2017. Vol 6 (1): $873-883$

whorls of RER formed by paired membranes. They were mainly oval or circular. These whorls encircled 2-3 mitochondria (Fig. 14).


Fig.11. EM of cells of the zona fasciculata showing oval nucleus (CF), intracellular lipid droplets (L) of varying size and lysosome-like structures (LY). Fig.12: EM of zona fasciculata showing cortical cells (CL), lipid droplets (L), mitochondria (M). Note the presence of venous sinuses. Some pyknotic cells are apparent (P). Fig.13: Higher EM of cells of zona fasciculate showing copious mitochondria of vesicular type and tubular types (M) and myelin figures (MF). Note the well developed intercellular junction. Fig.14: EM of cytoplasm of cells of zona fasciculate showing concentric whorls of rough endoplasmic reticulum (RE) enclosing mitochondria (M) of varying shape. Note the presence of free ribosomes (arrow) and tubular smooth endoplasmic reticulum (SE) and junctional complex (J). 
The zona reticularis (ZR) generally showed compact anastomosing cords of smaller cells that were similar in shape and size to that of ZF. However they contained less lipid droplets than that of ZF. Abundant mitochondria were evident. A consistent mesh-work of vascular sinusoids was present between cells in the ZR. SER was less prominent in this zone compared to ZF. Lysosome -like structures were encountered frequently here than in other zones and in places formed groups of 2-
3. Degenerating cells with pyknotic nuclei were commonly observed (Fig.15). Occasionally lipofuscin-like pigment granules were seen. Blood capillaries were frequently seen amongst these cells. Lipid droplets were generally sparse and no association of lipid droplets with mitochondria as was observed in the ZF. At the corticomedullary border, copious vascular elements were commonly observed in addition to collagen fibrils. Pyknotic cells nuclei were frequent.
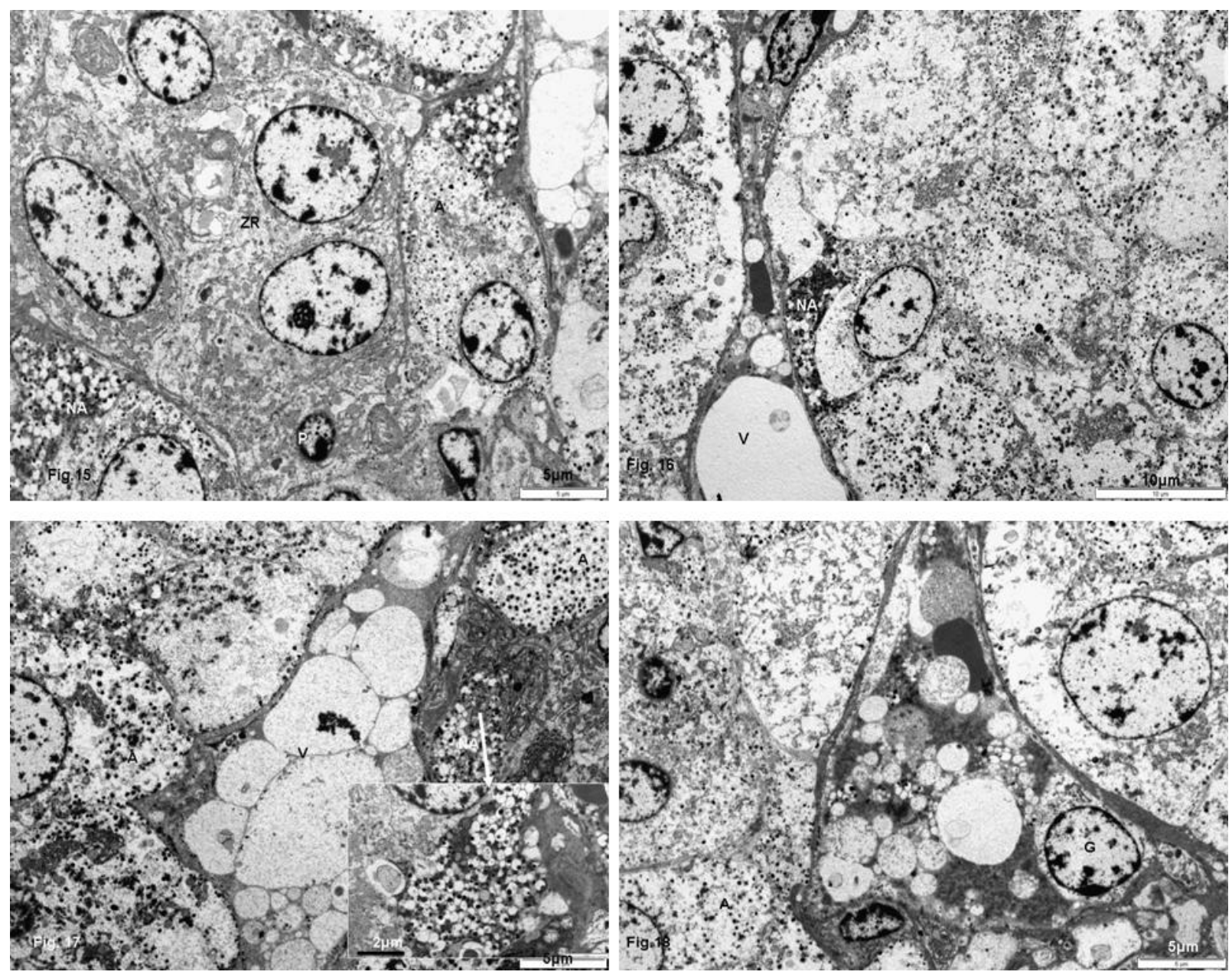

Fig.15: EM showing the cells of zona reticularis (ZR) close to the chromaffin cells of the medulla containing adrenalinestoring cells (A) and noradrenalin-storing cells (NA). Cells with pyknotic nuclei (P) were commonly observed here. Fig.16: EM of adrenal medulla showing chromaffin cells comprising of 2 types-those more numerous and smaller granules identified as adrenaline-storing cells $(A)$ and those with high electron dense materials eccentrically located within membrane-bound granules called noradrenaline-storing cells (NA). Note the copious venous sinuses (V). Fig. 17: EM of medulla showing copious adrenaline-storing cells $(A)$ and noradrenaline-storing cells (NA/insert) and intervening venous sinuses.Fig.18: EM of adrenal medulla showing chrommaffin cells-adrenaline-storing cells $(A)$ with occasional ganglion cells (G).

The adrenal medulla ultrastructural overview showed chromaffin cells lined by basement membrane and connective tissue. In between groups of cells were fibrocytes, collagen fibrils, large central blood sinusoids and nerve fibres. The chromaffin cells generally possessed large euchromatic nuclei and slight peripheral heterochromatin with prominent nucleolus that may be double. The cytoplasm also contained profiles of mitochondria, rough endoplasmic reticulum, few lysosomes and 
free ribosomes (Fig.16). The Golgi apparatus were not prominent compared to the cortical cells. Two types of chromaffin cells were identified; the adrenaline storing chromaffin cells $(A)$, were more numerous and smaller than the noradrenaline stroring cells (NA). The cytoplasm of A cells had less electrondense secretory granules than NA cells. Its fine rounded granular materials were scattered in the cytoplasm. The secretory granular materials of NA cells were electron dense and eccentrically located within the membrane-bound granules (Fig.17). The granules showed a clear space between the membrane and the granular content. Ganglion nerve cells with few vesicles were occasionally observed amongst chromaffin cells (Fig.18). Ganglion nerve cells contained large prominent nuclei, which were eccentrically placed. Several large vesicles were observed in the cytoplasm.

\section{DISCUSSION}

The adrenal gland produces a number of steroid hormones, catecholamines and a cocktail of glycoproteins, opoid-peptides and prohormone-processing enzymes (Crivellatoet al., 2008; Mitani, 2014). The histological features comprising prominent cortex, zonation of the cortex and a well-developed medullary parenchymal cell, complemented with typical ultrastructural features of adrenal parenchymal cells support a hyper-functional adrenal comparable to other rodents so far studied (Coupland, 1965; Nussdorfer et al., '1978; Yilmaz and Grigin, 2005) and several other mammals as reviewed earlier byIdelman, 1970 and Nussdorfer et al., 1978. However, few remarkable ultrastructural features in addition were observed in the present investigation warrant further comments

The capsule $(C)$, zona glomerulosa $(Z G)$, zona fasciculata (ZF) and zona reticularis (ZR) measured $25.7 \pm 4.4 \mu \mathrm{m}, 64.5 \pm 9.7 \mu \mathrm{m}$, $720.6 \pm 18.6 \mu \mathrm{m}$ and $106.3 \pm 14.5 \mu \mathrm{m}$ in thickness respectively, which is different fromvalues of $20.16 \pm 5.2 \mu \mathrm{m}, 67.44 \pm 9.5$, 494. $52 \pm 12.3 \mu \mathrm{m}$ and $157.17 \pm 23.6 \mu \mathrm{mfor}$ C, ZG, ZF and ZR thickness respectively, obtained in adult rats of 201 days (Janjua and Khan, 1992). The adrenal showed a prominent capsule, which ultrastrucuturally contained fibroblasts, nerve fibers and vascular tissue similar to some rodents including rabbit, mouse and rat (Coupland, 1965, 1968; Idelman, 1970).

The differences in thickness of cortical zones support a clear species variation in the size of the different zones of the adrenal gland which may also be due to environmental and climatic influences. The size of the cortex is also known to increase with age (Nussdorfer, 1986). There was indistinct boundary between the zones of the cortex, as they tend to merge gradually from one zone to another as in most rodents and this may also have influenced presently obtained values. In large animals, such as buffalo, there is distinction between the zones and quantitative measurement was very easy (Teixeira and Kramer, 1993).

The general ultrastructure of the cytoplasmic organelles in the adrenal cortex of the cane rats used in this study somewhat followed that described in several rodents including rat, guinea pig, hamster, mouse, rabbit (Idelman, 1970 and Nussdorfer,1986; Janjua and Khan, 1992) andporcupine (Yilmaz and Girgin, 2005). In the cortex, the cane rats, the presence of highly developed smooth endoplasmic reticulum (SER), profiles of mitochondria with varying shape, numerous lipid droplets, prominent Golgi complex, free ribosomes and patches of rough endoplasmic reticulum (RER) with variability of number in the zones of the cortex demonstrated its steroid hormone synthesizing ability. The structural features are associated with cholesterol and cholesterol esters stored in the lipid droplets. These substances are converted into definite hormones through a pathway involving enzymes present in the mitochondrial crista and SER tubules (Nussdorfer, 1986;Cuiet al., 2011). In addition, the presence of preponderant membranous whorls of RER that encircled 
about 2-3 oval mitochondria in the ZF-ZR boundary.Similar concentric whorls of RER have been described in the adrenocortical cells of the Mongolian gerbil Meriones unguiculatus (Kardioglu and Harrison, 1975; Nickerson, 1977). It has also been described in the interstitial cells of mouse testis and spermatocytes of Ascaris(Christensen and Fawcett, 1966)). These structures according to these authors suggested that they may arise during cellular degeneration, possibly as a compensatory reaction to cell injury.Nickerson and Curtis(1969) additionally proposed that the appearance of RER is to serve as reserve RER for synthesis of enzymes required in steroid production. The presence of whorled RER in the ZF-ZR border in this study represents a transitional stage between the ZF and ZR cells. It known that cells of the ZF may be transformed into compact cells resembling those present in the $Z R$. The surface area of the whorled RER membranes is increased and this may enhance steroid hormone synthesis.

Lipid droplets of small and large sizes were predominantly seen in the ZF, particularly in the inner aspect close to the ZR. Some animals like the mouse are known to lack them. Lipid droplets are abundant in the rat, scarce in the guinea pig, and virtually absent in the ox (Nussdorfer et al., 1978). A great number of studies reported a conspicuous decrease in the number and volume of lipid droplets during chronic adrenal stimulation (Nussdorfer et al., 1978). In hyper-functional state of the adrenal, the lipid droplets are smaller, while they are larger in hypo functional state (Kawai et al., 1979). The comparatively moderate number and size of lipid droplets in this study probably represent a state of unstimulated adrenal gland due to domesticated cage-environment, with less exposure to the stress of seeking for food.

In zona fasciculata, some mitochondria had myelin-like protrusions (blebs) extending from the outermembrane and often penetrating adjacent lipid droplet. Similar feature has been observed in the rat (Matsukuma, 1981), in the fetal adrenal zone in the armadillo (Enderset al., 1966) and some other mammals. Myelin figuresmay present degenerating stages of cortical cells engaged in steroid hormone synthesis.

The medulla measured about $636.5 \pm$ $11.5 \mu \mathrm{m}$ in thickness, which differed significantly from the value of $482.5 \pm 16.6$ $\mu \mathrm{m}$ obtained for the adult buffalo (Attia and Abdel-Rahman, 2013), a much bigger ruminant animal. It reflects variations relating to species and environmental differences.In the adrenal medulla of the cane rats fixed in glutaraldehyde and post-fixed in osmium tetroxide, the chromaffin cells displayed classical ultrastructural morphological features as initially described by Coupland (1965, 1971) and other researchers (Janjua and Khan 1992; Yilmaz and Girgin, 2005; Al Bustami and Al Tarawneh, 2015). The cytoplasm of the Adrenaline cells (A) contained copious rounded granules of various sizes and electron densities, whereas noradrenaline (NA) granules were irregular in shape and showed very dark often eccentric cores with swollen spaces within their limiting membranes. These ultrastructural features observed presently in the chromaffin cells suggest that they secrete a plethora of hormonal peptides, enzymatic and opoid substances that definitely help in their ability to adapt from the wild to domestic environment. It has been established in the first half of the last century that the chromaffin cells of the adrenal glands are an integral part of the sympathetic nervous system and release hormonal substances in response to acute stress. Chromaffin granules are membrane-bound and strongly electrondense. It originates from Golgi network (Crivellato et al., 2008).Some ganglion nerve cells were occasionally identified in the present investigation. They were small and irregular in shape, and extended attenuated processes closely making contact with chromaffin cells. They contained membranebound vesicles and small granule vesicles as described by some investigators (Coupland, 1965; Unsicker, 1973). These cells are actually bipolar or multipolar neurons which send post-ganglionic nerve fibers. Some of these vesicles have been shown to contain neuropeptides such somatostatin and enkephalins (Crivellato et al., 2008).

\section{Conclusion}


The study showed that the structure of the adrenal gland in the cane rats is similar to that of other rodents like the rat, guinea pig, hamster, mouse, rabbit and porcupine. Few remarkable features such as copious lipid droplets and prominent concentric whorls of RER in the cortexis essential for adaptation to the environment.

\section{Acknowledgement}

The author is grateful to Ms. Erna Van Wilpe and Lizette Du Plessis of the EM unit, Department of Anatomy/ Physiology, Faculty of Veterinary Science, University of Pretotia, South Africa, for their technical support.

Conflict of Interest: The author declares that there is no conflict of interest regarding the publication of this paper.

\section{REFERENCES}

1. Al-Bustami F, Al-Tarawneh I. 2015. Factors affecting differentiation of small granule chromaffin (SGC) cells of the mouse adrenal medulla. Intern J Adv Res Biol Sci2: 148-157.

2. Attia HF, Abdel-Rahman, GH. 2013. Histological, morphometric and ultrastructure of the buffalo adrenal gland.http://www.uaiasi.ro/simpozion_med/Revista/volumcurent.php[accessed July, 2015]

3. Christensen AK, Fawcett DW. 1966. The fine structure of testicular interstitial cells in the mice. Amer] Anat 118:551-571.

4. Coupland RE.1965.Electron microscopic observations on the structure of the rat adrenal medulla. J Anat 199: 231-251.

5. Coupland, RE.1971. Observations on the form a size distribution of chromaffin granules and on the density of adrenaline and noradrenaline-storing granules in tissue fixed in glutaraldehyde. Memo Soc Endocrinol 19: 611-635.

6. Crivellato E, Nico B, Rinatti D. 2008. The chromaffin vesicle: Advances in the understanding the composition of a versatile, multifunctional secretory organelle. Anat Rec 291: 587-1602.

7. Cui D, Naftel JP, Daley WP, Lynch JC, Hounes DE, Yang GY, Fratkin JD. 2011.Atlas of Histology with Functional and Clinical correlations, Wolters Kluwer and Lippincott Williams and Wilkins, Philadelphia, p.336-338.

8. Enders AC, Schlafke S, Warren R. 1966. Cytology of the fetal zone of the adrenal gland of the armadillo. Anat Rec 154:807-821.

9. Hullinger R,Adrisani OM. 2006.Endocrine system. In: Dellman's Textbook of Veterinary Histology, $6^{\text {th }}$ edn (JAC Eurell, BL Frappier and HD Dellman, eds), Ames; Blackwell Publishing, p.298-319.

10. Idelman S. 1970. Ultrastructure of mammalian adrenal cortex. Inter Rev Cytol 27: 181-273.

11. Ishimura K, Fujita H. 1997. Light and electron microscopic immunohistochemistry of the localization of adrenal steroidogenic enzymes. Microsc Res Tech 36: 445-453.

12. Janjua MZ, Khan MY. 1992. Age-related changes in the rat adrenal cortex. Jinna Postgrad Med Arch (JPMA) 42: 89

13. Jelinek F, Konecny R.2011. Adrenal glands of slaughtered bulls, heifers and cows: $A$ Histological study. Anat Histol Embryol 40: 28-34.

14. Kardioglu D, and Harrison RG. 1975. The ultrastructure of the adrenal cortex of the Mongolian gerbil (M. unguilatus). J Anat 120: 179-189.

15. Kawai K, Sugikhar A, Tsuchiyama H. 1979. The effect of low potassium diet on the glomerular zone of the adrenal cortex of rat. Pathol Intern 29:351-362.

16. Kobayashi S, Coupland RE.1993. Morphological aspects of chromaffin tissue: the differential fixation of adrenaline and noradrenaline. J Anat 183: 223-235.

17. Liggins GC.1976. Adrenocortical-related maturation events in the fetus. Amer J Obstet Gynaecol126: 931-941. 
18. Mastukuma H. 1981.An ultrastructural and stereological study of the lipid droplets of adrenal cortex of rats fed with high fat, low protein and cholesterol supplements. Acta Medica Nagasakiensia 26:56-72.

19. Messiano S, Jaffe R.1997.Development and functional biology of primate fetal adrenal gland. Endocr Rev 78: 378-403.

20. Mitani F.1969.Functional zonation of the rat adrenal cortex: the development and maintenance. Proc Jap Acad Sci B90: 163-183.

21. Nickerson PA, Curtis JC.1969.Concentric whorls of rough endoplasmic reticulum in adrenocortical cells of the Mongolian gerbil. JCell Biol 40: 859-862.

22. NIckerson PA. 1977.Formation of concentric whorls of rough endoplasmic reticulum in the adrenal gland of the Mongolian gerbil. J Anat 124:383-391.

23. Nussdorfer GG, Mazzocchi G, Virgilio M.1978. Cytophysiology of the adrenal zona fasciculata. Intern Rev Cytol 55: 291-365.

24. Nussdorfer GG. 1980.Cytophysiology of the adrenal zona glomerulosa. International Rev Cytol 64: 307367.

25. Nussdorfer GG.1986. Cytophysiology of the adrenal cortex. Intern Rev Cytol 98:1-405.

26. Teixeira M,Kramer B. 1993. The Adrenal gland of the African Buffalo (Syncerus caffer): a light and electron microscopic study. South Afr J Zool 28:13-17.

27. Unsicker K. 1973. Fine structure and innervation of the avian adrenal gland. I. Fine structure of adrenal chromaffin cells and ganglion cells. Z Zellforsch 145: 389-416.

28. Yilmaz S, Aydin G. 2005. Light and electron microscopic observations on the structure of the porcupine (Hystrax cristata) adrenal gland. Veterinarski Arhiv 75:265-272. 